\title{
Prediction of the Mechanism of miRNAs in Laryngeal Squamous Cell Carcinoma based on the miRNA-mRNA Regulatory Network
}

\author{
Jinhua Ma ${ }^{1}$, Xiaodong Hu ${ }^{1}$, Baoqiang Dai ${ }^{1}$, Qiang Wang ${ }^{1}$, Hongqin Wang ${ }^{\text {Corresp. } 1}$ \\ ${ }^{1}$ Department of Otolaryngology, Cangzhou Central Hospital, Cangzhou, China \\ Corresponding Author: Hongqin Wang \\ Email address: hongqinwang0317@126.com
}

In this study, a bioinformatics analysis is conducted to screen differentially expressed miRNAs and mRNAs in laryngeal squamous cell carcinoma (LSCC). Based on this information, we explore the possible roles of miRNAs in the pathogenesis of LSCC. The RNA-Seq data from 79 laryngeal cancer samples in Gene Expression Omnibus (GEO) database are sorted. Differentially expressed miRNAs and mRNAs in LSCC are screened using the PERL programming language, and it was analysed by gene ontology (GO) and Kyoto Encyclopaedia of Genes and Genomes (KEGG). The miRNA-mRNA regulatory network of LSCC is constructed using Cytoscape software. Then, Quantitative real-time PCR (QRTPCR), Cell Counting Kit-8 (CCK8) and Flow cytometry analysis are used to further validate key miRNAs. We identify 99 differentially expressed miRNAs and 2758 differentially expressed mRNAs in LSCC tissues from the GEO database. Four more important miRNAs displaying a high degree of connectivity are selected, these results suggest that they play an important role in the pathogenesis of LSCC. As shown in the present study, we identified specific miRNA-mRNA networks associated with the occurrence and development of LSCC through bioinformatics analysis. We found a miRNA molecule closely related to LSCC based on miRNA-mRNA network: miR-140-3p was down-regulated in LSCC. In addition, the potential antitumor effect of miR-140-3p in LSCC was verified in the experiment, and it was proved that overexpression of miR-140-3p could inhibit the proliferation of LSCC cells and promote cell apoptosis, suggesting that miR-140-3p may be a potential tumor marker in LSCC. 
1 Prediction of the Mechanism of miRNAs in Laryngeal Squamous Cell Carcinoma based on

$4{ }^{1}$ Department of Otolaryngology, Cangzhou Central Hospital, Cangzhou, 061001 China.

the miRNA-mRNA Regulatory Network

\author{
Jinhua $\mathrm{Ma}^{1}$, Xiaodong $\mathrm{Hu}^{1}$, Baoqiang Dai ${ }^{1}$, Qiang Wang ${ }^{1}$, Hongqin Wang ${ }^{1}$
}

5 Correspondence to: Hongqin Wang E-mail: hongqinwang0317@126.com

6 Department of Otolaryngology, Cangzhou Central Hospital, Cangzhou, 061001 China.

7 Abstract: In this study, a bioinformatics analysis is conducted to screen differentially expressed 8 miRNAs and mRNAs in laryngeal squamous cell carcinoma (LSCC). Based on this information, 9 we explore the possible roles of miRNAs in the pathogenesis of LSCC. The RNA-Seq data from 1079 laryngeal cancer samples in Gene Expression Omnibus (GEO) database are sorted. 11 Differentially expressed miRNAs and mRNAs in LSCC are screened using the PERL 12 programming language, and it was analysed by gene ontology (GO) and Kyoto Encyclopaedia of 13 Genes and Genomes (KEGG). The miRNA-mRNA regulatory network of LSCC is constructed using Cytoscape software. Then, Quantitative real-time PCR (QRT- PCR), Cell Counting Kit-8 (CCK8) and Flow cytometry analysis are used to further validate key miRNAs. We identify 99 differentially expressed miRNAs and 2758 differentially expressed mRNAs in LSCC tissues from the GEO database. Four more important miRNAs displaying a high degree of connectivity are selected, these results suggest that they play an important role in the pathogenesis of LSCC. As shown in the present study, specific miRNA-mRNA networks are associated with the occurrence and development of LSCC. Bioinformatics analysis and QRT- PCR results show that miR-140-3p is downregulated in LSCC, miR-140-3p overexpression inhibits LSCC cell proliferation and promotes apoptosis. This study identifies effective and reliable diagnostic and prognostic molecular biomarkers through an integrated bioinformatics analysis and experimental verification, providing theoretical support for the identification tumour markers for assessing the diagnosis, treatment and prognosis of LSCC. 


\section{Introduction}

Head and neck squamous cell carcinoma (HNSCC) is the sixth most common malignancy, and LSCC is a common malignant tumor of HNSCC deriving from the laryngeal mucosal epithelium (Lampri et al., 2015; Wei et al., 2018; Xiong et al., 2020). LSCC causes great pain in patients, seriously threatens the health of humans, and increases the economic burden on patients and the society. In 2015, there were approximately 25,300 cases of laryngeal cancer in China; and the incidence rate of laryngeal cancer ranked the $21 \mathrm{st}$ in all malignant tumors, most of these patients are middle-aged and elderly men (He et al., 2020). At present, the primary diagnosis of LSCC mainly depends on the medical history, physical examination of the head and neck, laryngoscopy, imaging examination and other auxiliary examinations, and the diagnosis of LSCC must also rely on the pathological tissue biopsy results. Previous literature also showed that miR-941, miR-21 and miR-27a were potential diagnostic markers of LSCC (Yu et al., 2014; Zhao et al., 2020). Surgery is still the main treatment for LSCC, and the survival rate of LSCC has not improved significantly in recent years, which is caused by the lack of understanding of the mechanism of occurrence and progression of LSCC (Chen et al., 2016). With the development of research, more and more microRNAs (miRNAs) have opened a mysterious door for the diagnosis and treatment of LSCC. Therefore, it is imperative to further explore and elucidate the pathogenesis of LSCC, identify new biomarkers, and study new effective therapeutic targets.

MiRNAs are an endogenous single-stranded noncoding RNA that regulate gene expression, with a length of approximately 18 to 22 nucleotides. These non-coding RNAs were discovered by Lee et al in 1993 (Lee et al., 1993). In the transcription process, the miRNA gene is first transcribed in the nucleus to form the original transcript, namely, a pri-miRNA with stem ring structure of approximately 300 to 1000 nucleotides. Subsequently, the original transcript is processed through further splicing into a functional, mature miRNA and transported into the cytoplasm, where it selectively binds to complementary mRNAs to inhibit protein production and regulate gene 
52 expression. Notably, miRNAs are highly conserved and widely exist in animals, plants, viruses 53 and other organisms (Baril et al., 2015; Vishnoi \& Rani, 2017). Studies have shown that miRNAs 54 regulate approximately one-third of the mRNAs in the body and thus participate in a variety of 55 biological processes in humans (Wang et al., 2020). A large number of studies have shown that miRNAs play an important role in inhibiting or promoting cancer growth by regulating the mRNAs encoded by tumour suppressor genes or oncogenes, affecting the occurrence, development, metastasis and recurrence of tumours (Wu et al., 2016; Qadir \& Faheem, 2017; Wang et al., 2020). Notably, miRNAs influence the occurrence, development and metastasis of LSCC through complex mechanisms, and thus the discovery of new miRNAs in LSCC tissues is very important for the diagnosis and treatment of $\operatorname{LSCC}(\mathrm{Liu} \& \mathrm{Ye}, 2019)$. The purposes of this study were to screen for differentially expressed miRNAs and mRNAs in LSCC using molecular biology and bioinformatics techniques, to successfully predict miRNA target genes, and to construct a miRNAmRNA regulatory network based on the relationships between miRNAs, mRNA, of miRNA target genes and differential expression (Guan et al., 2015; Fei et al., 2017; Ma et al., 2021). Next, further evaluation was performed using gene ontology (GO) and Kyoto Encyclopaedia for gene and genome (KEGG) path analysis. Then, perform QRT- PCR, CCK8 and Flow cytometry analysis to further validate key miRNAs. This study provides a new method to explore the pathogenesis of LSCC at the molecular level, as well as a new reference and direction for the search for molecular markers to diagnose LSCC and new therapeutic methods.

\section{Materials and methods}

Sample source

LSCC miRNA and mRNA chip data were collected from the GSE124678 and GSE59102 retrieved from the National Center for Biotechnology Information (NCBI) GEO Datasets (http://www.ncbi.nlm.nih.gov/geo). Derived from the GPL16770 platform, GSE124678 includes 5 normal tissue samples and 32 tumor tissue samples. Derived from the GPL6480 platform, GSE59102 includes 13 normal tissue samples and 29 tumor tissue samples. The miRNA and 
mRNA microarray data of LSCC and normal laryngeal tissues were processed using platform annotation file (Edgar et al., 2002). We then used PERL5.30.2 (https://www.PERL.org/) to analyze and process the dataset; according to the annotation platform file of the expression profile, the probe name was converted to the corresponding gene name, and the empty probe was removed. Then, the miRNA and mRNA data were obtained by sequencing the data from the two datasets in order of the normal group and the tumor group.

\section{Analysis of differentially expressed miRNAs and mRNAs}

We used the LIMMA software package from $\mathrm{R}$ software (https://rstudio.com/, ver. 3.6.2). Objective to screen miRNAs and mRNAs differentially expressed in LSCC (Colaprico et al., 2016). The screening criteria we set are: $\mid \log 2$ (fold change) $\mid>1$ and FDR (False Discovery Rate) $<0.05$. Then, the "pheatmap" package and "ggplot2" package in R (3.6.2) were used to produce the volcano map. The differentially expressed miRNAs and mRNAs were screened.

\section{Prediction of miRNA targets}

The effects of miRNAs are mediated by their complete or incomplete interactions with target genes, affect the expression of target genes. Hence, miRNAs target genes must be predicted. In this study, 99 differentially expressed miRNAs target genes were predicted by FunRich (3.1.3).

\section{Construction of the miRNA-mRNA regulatory network diagram}

First, we used PERL software to intersect the target genes of miRNAs with the differentially expressed mRNAs in LSCC to obtain the common mRNAs and corresponding miRNAs. Previously, a negative regulatory relationship between miRNAs and their target genes was identified (Bartel, 2009). Therefore, based on the negative regulatory relationship between miRNAs and mRNAs, miRNA-mRNA pairs with significant differences in $\log 2$ (fold change) values were selected, and Cytoscape (3.7.2) software was used to visualize the regulatory network 
101 between the two to obtain the miRNA-mRNA regulatory network (Lin \& Chen, 2018; Zhao et al., 102 2020).

104 We performed GO and KEGG enrichment analyses of differentially expressed mRNAs to further

105 clarify the biological functions of target genes in the regulatory network (Kanehisa \& Goto, 2000;

106 Khatri et al., 2012). R software in the Bio-conductor plug-in (http://www.Bioconductor.org) was

107 used to perform the GO and KEGG enrichment analyses with the criteria of $p<0.05$ and $q<0.05$.

108 The results are given in the form of bar chart.

\section{Cell Culture and Cell Transfection}

110 We used Human LSCC cell line LSC-1 (Bluefbio, China) and human laryngeal epithelial cells

111 (HLEC; Lifeline, America). Dulbecco's Modified Eagle's medium (DMEM) was used as the basic

112 medium and $10 \%$ foetal bovine serum (FBS) and $100 \mathrm{~g} / \mathrm{ml}$ penicillin/streptomycin were added to

113 the medium, the culture conditions were $37^{\circ} \mathrm{C}$ and $5 \% \mathrm{CO}_{2}$. In this study, the cells were all used at 114 passages 2-4 after recovery.

115 5nmol miR-140-3p miRNA mimics (miR-140-3p) or miRNA mimic negative control (miR-NC)

116 (GENECREATE, Wuhan, China) was dissolved in $0.9 \% \mathrm{NaCl}$ as a storage solution of $20 \mu \mathrm{M}$.

117 LSC-1 cells (3*105 cells per well) were cultured in 6-well plates overnight. When cell density

118 reached $60-70 \%$, the cell medium was replaced with a complete medium without antibiotics. 1.5 $119 \mu \mathrm{L}$ of miR-140-3p or miR-NC storage solution was diluted with $50 \mu \mathrm{L}$ serum-free medium, and 1

$120 \mu \mathrm{L}$ Lipofectamine ${ }^{2000}$ (Beyotime, Shanghai, China) was added to the other $50 \mu \mathrm{L}$ serum-free

121 medium. Mix well and let stand at $37^{\circ} \mathrm{C}$ for $5 \mathrm{~min}$. Mix the two tubes together and let stand at $37^{\circ} \mathrm{C}$

122 for $20 \mathrm{~min}$. Then add the mixture into each cell well, gently shake the culture plate to mix the 123 complex with the cells, add $500 \mu \mathrm{L}$ complete medium, and place in the cell incubator for further

124 culture for $48 \mathrm{~h}$, then collect the cells for subsequent experiments. All cells were cultured in 
125 complete medium for at least $24 \mathrm{~h}$ before transfection and rinsed with phosphate-buffered saline

126 (PBS, pH 7.4) before transient transfection. The generated cell clones were tested for stable miR-

127 140-3p expression.

128

129

130

131

132

133

134

135

136

137

138

139

140

141

142

143

144

145

146

147

148

$R N A$ Extraction and QRT-PCR

According to the manufacturer's instructions, total RNA was extracted from the cell using Trizol reagent (TAKARA, Japan). Total RNA was reverse transcribed into cDNA using the PrimeScript RT Reagent Kit (Takara, Japan). Reverse transcription: $25^{\circ} \mathrm{C} 10 \mathrm{~min}, 50^{\circ} \mathrm{C}$ for $30 \mathrm{~min}$ and $85^{\circ} \mathrm{C}$ for 5 min. Expression was detected using the fluorescence quantitative PCR kit and the following conditions: there are 40 cycles at $95^{\circ} \mathrm{C}$ for $5 \mathrm{~min}, 95^{\circ} \mathrm{C}$ for $10 \mathrm{~s}, 60^{\circ} \mathrm{C}$ for $30 \mathrm{~s}$. The solubility curve temperature was set to $60-95^{\circ} \mathrm{C}$, and three replicate wells were set for each specimen. The expression of miR-140 was normalized to a small nuclear RNA (U6) as an internal reference. The results were calculated using the $2^{-\Delta \Delta \mathrm{Ct}}$ method. The primer sequences used for quantitative realtime PCR analyses of $\operatorname{miR}-140-3 p$ were as follows: forward, 5'ACACTCCAGCTGGGTACCACAGGGTAGAA-3' and reverse, 5'CtCAACTGGTGtCGTGGAGTCGGCAATtCAGTtGAGCCGTGGTT-3’. The primer sequences for small nuclear RNA (u6) are as follows: forward, 5'- CTCGCTTCGGCAGCACA 3' and reverse 5'- AACGCTTCACGAATTTGCGT -3'. The relative expression of miRNA was detected by $2^{-\Delta \Delta \mathrm{Ct}}$.

\section{CCK8 assay}

We performed the CCK8 assay to measure the proliferation of LSC-1 cells. Cells were cultured in 96-well culture plate, and the inoculation density was $3 * 10^{5} /$ well (Jiang et al., 2019). For cell transfection, cells were cultured overnight. After 48 hours of transfection, $10 \mathrm{~mL}$ of CCK8 solution was added to each well, and the cells were incubated at $37^{\circ} \mathrm{C}$ for another $60 \mathrm{~min}$. The absorbance of the solution was measured at 490nm by Smart Microplate Reader (SMR) 16.1. 
150 LSC-1 cells were transfected for $48 \mathrm{~h}$. After transfection with miR-140-3p mimics or control 151 miRNA, LSC-1 cells were washed with cold PBS buffer. Then, LSC-1 cells were detached with

152 trypsin and washed twice with cold PBS. According to the manufacturer's instructions, cells were 153 subsequently double stained with FITC-labelled Annexin V and propidium iodide (PI) using the

154 FITC Annexin V Apoptosis Detection Kit (BD Biosciences, USA). Flow cytometer was performed 155 to determine the percentage of apoptotic cells (FACS Calibur; BD Biosciences, USA). The data 156 were analyzed by FLOWJ software.

157 Statistical Analysis

158 GraphPad Prism5.0 and statistical product and service solutions (SPSS) 22.0 software were used 159 for statistical analyses. Use t-test to enumeration data, and $\mathrm{P}<0.05$ indicated the significance level.

\section{Results}

\section{Differentially expressed miRNAs and $m R N A s$}

162 After annotating the GSE124678 dataset, 1205 pieces of miRNA information were obtained from

163 human laryngeal carcinoma tissues, including 5 tissues in the normal group and 32 tissues in the 164 tumour group. 99 differentially expressed miRNAs were screened by PERL

165 language (Supplementary file, Table S1 for details). A volcanic map of differentially expressed 166 miRNAs is then drawn using R software (Figure 1). Similarly, we used the GSE59102 dataset 167 from the LSCC mRNA chip downloaded from the GEO database to create a volcanic map of the 168 differentially expressed mRNAs for human LSCC (Figure 2). 13 tissues in the normal group and

16929 tissues in the tumour group were analysed. A total of 2758 differentially expressed mRNA, 170 were obtained, including 1312 up-regulated and 1446 down-regulated (Supplementary file, Table 171 S2 for details). 
172

173 FunRich (3.1.3), a gene function analysis tool, was used to predict the target genes of the 99

174 differentially expressed miRNAs; 1386 target genes were obtained in the background, and the

175 number of miRNAs matched with them was 32 .

\section{Construction of the miRNA-mRNA network diagram}

177 The differentially expressed mRNAs and predicted miRNA target genes in laryngeal carcinoma

178 were processed using PERL. The intersection of miRNA target gene and mRNAs, that is, the 179 targeted regulation relationship between miRNAs and mRNAs, was obtained. Then, Cytoscape 180 software was used to map the miRNA-mRNA regulatory network (Figure 3). This miRNA-mRNA 181 regulatory network contains 10 miRNAs and 96 mRNAs (Supplementary file, Table S3 for

182 details). The more genes that are connected with miRNAs in this regulatory network indicate that 183 this miRNA is very important in the occurrence and development of LSCC. As this regulatory 184 network clearly shows, miR-140-3p regulates more mRNAs. It is suggested that miR-140-3p plays 185 an important role in the occurrence and development of LSCC.

Functional enrichment analysis

187 We conducted GO and KEGG enrichment analyses of the 2758 differentially expressed mRNAs 188 using $p<0.05$ and $q<0.05$ as screening conditions. The GO analysis includes three categories: 189 molecular function (MF), cellular component (CC), and biological process (BP). These 190 differentially expressed mRNAs promoted the occurrence and development of LSCC by

191 participating in various BPs, CCs and MFs (Figure 4). Similarly, the results of KEGG enrichment 192 analysis were also included Cell cycle (hsa04110), p53 signaling pathway (hsa04115), IL-17 193 signaling pathway (hsa04657), chemical carcinogenicity (hsa05204), etc (Figure 5, Table1).

194 The expression of miR-140-3p in LSC-1 cells is low 
195 In this study, the expression of miR-140-3p in LSC-1 cells and HLECs was detected using QRT-

196 PCR. We examined the expression of miR-140-3p in HLECs and LSC-1 cells, and observed lower

197 miR-140-3p expression in LSC-1 cells than in HLECs. Obviously, these experimental results

198 suggest that the decrease in miR-140-3p expression in LSC-1 cells. The results were consistent

199 with bioinformatics analysis (Figure 6).

Upregulation of miR-140-3p expression inhibits LSC-1 cells proliferation in vitro

201 The CCK8 assay was performed to further assess the biological role of miR-140-3p in LSC-1 cells.

202 LSC-1 cells were transfected with miR-NC or miR-140-3p mimics. Cell proliferation was detected

203 by CCK8 method. QRT- PCR results showed that the transfection of miR-140-3p mimics led to

204 overexpression of miR-140-3p in LSC-1 cells compared with the control group (Figure 7).

205 Similarly, the results of the CCK8 assay showed significantly impaired growth of LSC-1 cells

206 transfected with miR-140-3p mimics compared with LSC-1 cells transfected with miR-NC. Based

207 on these results, the high expression of miR-140-3p in LSC-1 cells inhibited their proliferation

208 (Figure 8).

209 The upregulation of miR-140-3p promoted the apoptosis of LSC-1 cells

210 Flow cytometry was used to further clarify the effect of miR-140-3p upregulation on the apoptosis

211 of LSC-1 cells. Compared with miR-NC, miR-140-3p mimics significantly promoted the apoptosis

212 of LSCC cells. Thus, the upregulation of miR-140-3p promoted the apoptosis of LSC-1 cells

213 (Figure 9).

\section{Discussion}

215 In recent years, the incidence of LSCC and other types of malignant tumours has been

216 increasing year by year, while the survival rates of patients with LSCC have improved with

217 advances in medical technology for LSCC, such as surgery, radiotherapy and chemotherapy and

218 targeted therapy; however, the complications after surgery, radiation and chemotherapy still afflict 
219 patients with LSCC (Jin et al., 2011). Therefore, understanding LSCC from a molecular 220 perspective is particularly important (Huang et al., 2020).

221 Importantly, miRNAs regulate approximately one-third of human genes and play a key role 222 in the pathogenesis of malignant tumours. According to numerous studies, miRNAs are 223 abnormally expressed in the tissues and cells of malignant tumours, examples include breast cancer 224 (Wang et al., 2019), gastric cancer (Chen et al., 2019), thyroid cancer (Li et al., 2013), colorectal 225 cancer(Balacescu et al., 2018) and cervical cancer (Qu et al., 2018). Based on accumulating

226

227

228

229

230

231

232

233

234

235

236

237

238

239

240

241

242

243

244

evidence, the expression of miRNA is closely related to the prognosis of laryngeal carcinoma ( $\mathrm{Li}$ et al., 2016; Zhang et al., 2018). Moreover, miRNAs such as miR-199b-5p, miR-424-5p, miR1297 and miR-145-5p have been found to further participate in the occurrence and progression of LSCC by regulating their respective target genes (Gao et al., 2019; Li et al., 2019; Ashirbekov et al., 2020). Thus, miRNAs may be new biomarkers for the occurrence and progression of LSCC.

In this study, bioinformatics was used to analyse two GEO datasets, and 99 miRNAs and 2758 mRNAs were screened for differential expression between the normal group and the tumour group. Then, the regulatory networks of miRNAs and mRNAs in LSCC were systematically analysed. Functional GO and KEGG enrichment analyses revealed the potential roles of noncoding RNAs and coding RNAs in the development of LSCC. On the basis of the negative regulatory relationship between miRNAs and mRNAs, we constructed a network diagram containing 10 miRNAs and $96 \mathrm{mRNAs}$ for the purpose of better understanding the pathogenesis of LSCC. From the network diagram, we conclude that miR-140-3p is the miRNA that is most densely connected to other mRNAs in the targeted regulatory network.

Initially, Wienholds $\mathrm{E}$, et al identified a role for miR-140 in cartilage development in vivo (Wienholds et al., 2005). Notably, miR-140-3p belongs to the miR-140 cluster and has been shown to play an important role in the occurrence and development of a variety of tumours; miR-140-3p inhibits the proliferation of human cervical cancer cells by targeting RRM2 to induce cell cycle arrest and early apoptosis (Ma et al., 2020). Upregulation of miR-140 inhibits the proliferation and

Peer] reviewing PDF | (2021:03:59406:2:1:NEW 23 Jul 2021) 
245 invasion of colorectal cancer (Zhang et al., 2015), and miR-140-3p expression is decreased in 246 patients with breast cancer (Salem et al., 2016). Additionally, miR-140-3p inhibits the growth of 247 colorectal cancer cells and promote apoptosis by regulating programmed cell-death 1 ligand 1 (PD248 L1) (Jiang et al., 2019). Nevertheless, the expression and function of miR-140-3p in LSCC 249 development remains unclear. In this study, we found that the expression of miR-140-3p decreased 250 in LSCC. In addition, overexpression of miR-140-3p significantly reduced proliferation and 251 induced LSC-1 cells apoptosis in vitro. Based on these results, miR-140-3p plays an important role 252 in the occurrence and progression of LSCC. Therefore, we propose that miR-140-3p plays a 253 potentially important role in the development of LSCC cells.

254 Finally, the results obtained from the KEGG enrichment analysis again verified the results of the $255 \mathrm{GO}$ analysis. In the GO term enrichment analysis, the differentially expressed mRNAs were 256 importantly connected with the terms 'extracellular matrix organization', 'extracellular matrix 257 component', 'nuclear DNA replication' and 'mitotic nuclear division'. KEGG pathway analysis 258 indicated that the roles of the differentially expressed mRNAs were enriched in 'ECM-receptor 259 interaction', 'DNA replication', 'Cell cycle', 'p53 signalling pathway' and 'complement and 260 coagulation cascades'. The extracellular matrix (ECM) is composed of and interlocking mesh of 261 water, minerals, proteins secreted by resident cells, which is responsible for cell-cell 262 communication, cell adhesion and cell proliferation (Frantz et al., 2010). In the tumor tissue, ECM 263 surrounds tumour cells and plays vial functions in tumour progression and migration (Walker et 264 al., 2018). Cell cycle plays an important role in the development of tumours by affecting cell 265 proliferation and apoptosis (Kar, 2016). P53 is a tumor suppressor that is closely involved in DNA 266 repair, cell cycle arrest and apoptosis. P53 plays an anti-tumor role by promoting apoptosis, 267 maintaining genomic stability and inhibiting tumor angiogenesis (Golubovskaya \& Cance, 2013).

268 Yang et al found that DIAPH1 was highly expressed in LSCC and inhibited the apoptosis of LSCC 269 tumor cells by inhibiting the p53 signalling pathway (Yang et al., 2019).In addition, other pathways 270 identified in the KEGG enrichment analysis, for example IL-17 signalling pathway, chemical 271 carcinogenicity, and the interaction of viral proteins with cytokines and cytokine receptors, also 
272 suggest that these miRNA target genes are closely related to the occurrence of LSCC. IL-17

273 inhibits the apoptosis of LSCC cells, thus promoting the continuous growth of tumour cells (Wang

274 et al., 2013; Li et al., 2016). In addition, smoking and viral infection are causes of LSCC (Münger

275 et al., 2004; Bodnar et al., 2009; Huangfu et al., 2016; Tong et al., 2018; Kontić et al., 2019).

276 Tobacco has been shown to cause abnormal gene expression in the body, break the double-stranded

277 human DNA and downregulate the expression of repair genes in the body, thus promoting the

278 occurrence of cancer (Pawlowska et al., 2009; Sabitha et al., 2010). We hypothesized that

279 miRNAs may promote the occurrence of LSCC by regulating key target genes in these pathways,

280 but the specific regulatory mechanism remains unclear.

\section{Conclusion}

282 In conclusion, this study identified specific miRNA-mRNA networks associated with the 283 occurrence and development of LSCC through bioinformatics analysis. We found a miRNA 284 molecule closely related to LSCC based on miRNA-mRNA network :miR-140-3p was down285 regulated in LSCC. In addition, the potential antitumor effect of miR-140-3p in LSCC was verified 286 in the experiment, and it was proved that overexpression of miR-140-3p could inhibit the 287 proliferation of LSCC cells and promote cell apoptosis. This provides theoretical support for the 288 discovery of potential tumor markers for the diagnosis, treatment and prognosis of LSCC. 289 Although we have further revealed the role of miRNAs in the occurrence and development of 290 LSCC through a series of experiments, the pathogenesis of LSCC involves numerous molecular 291 interactions, which is only a small part of the pathogenesis of LSCC. Although we have found the 292 potential tumor suppressor effect of miR-140-3p in LSCC, there are still some deficiencies in this 293 study, and further in vitro and in vivo experiments are needed to verify the specific regulatory 294 mechanism of miR-140-3p in LSCC.

\section{Competing interests}

296 The authors declare that they have no competing interests. 

G, Sharipov K, Aitkhozhina N. 2020. Combination of circulating miR-145-5p/miR-191-5p as biomarker for breast cancer detection. PeerJ 8:e10494 DOI 10.7717/peerj.10494.

303

304

305

Balacescu O, Sur D, Cainap C, Visan S, Cruceriu D, Manzat-Saplacan R, Muresan MS, Balacescu L, Lisencu C, Irimie A. 2018. The Impact of miRNA in Colorectal Cancer Progression and Its Liver Metastases. International journal of molecular sciences 19(12)DOI 10.3390/ijms19123711.

Baril P, Ezzine S, Pichon C. 2015. Monitoring the spatiotemporal activities of miRNAs in small animal models using molecular imaging modalities. International journal of molecular sciences 16(3):4947-4972 DOI 10.3390/ijms16034947.

Bartel DP. 2009. MicroRNAs: target recognition and regulatory functions. Cell 136(2):215-233 DOI 10.1016/j.cell.2009.01.002.

Bodnar M, Rekwirowicz H, Burduk P, Bilewicz R, Kaźmierczak W, Marszałek A. 2009. [Impact of tobacco smoking on biologic background of laryngeal squamous cell carcinoma]. Przegla, lekarski 66(10):598-602

Chen J, Wu L, Sun Y, Yin Q, Chen X, Liang S, Meng Q, Long H, Li F, Luo C, Xiao X. 2019. Mir-421 in plasma as a potential diagnostic biomarker for precancerous gastric lesions and early gastric cancer. PeerJ 7:e7002 DOI 10.7717 peerj.7002.

Chen W, Zheng R, Baade PD, Zhang S, Zeng H, Bray F, Jemal A, Yu XQ, He J. 2016. Cancer statistics in China, 2015. CA: a cancer journal for clinicians 66(2):115-132 DOI 10.3322/caac.21338.

Colaprico A, Silva TC, Olsen C, Garofano L, Cava C, Garolini D, Sabedot TS, Malta TM, Pagnotta SM, Castiglioni I, Ceccarelli M, Bontempi G, Noushmehr H. 2016. TCGAbiolinks: an R/Bioconductor package for integrative analysis of TCGA data. Nucleic acids research 44(8):e71 DOI 10.1093/nar/gkv1507. 
319 Edgar R, Domrachev M, Lash AE. 2002. Gene Expression Omnibus: NCBI gene expression and hybridization array data repository. Nucleic acids research 30(1):207-210 DOI 10.1093/nar/30.1.207.

321

322

323

324

325

326

327

328

329

330

331

332

333

334

335

336

337

338

339

340

Fei Y, Guo P, Wang F, Li H, Lei Y, Li W, Xun X, Lu F. 2017. Identification of miRNA-mRNA crosstalk in laryngeal squamous cell carcinoma. Molecular medicine reports 16(4):4179-4186 DOI 10.3892/mmr.2017.7123.

Frantz C, Stewart KM, Weaver VM. 2010. The extracellular matrix at a glance. Journal of cell science 123(Pt 24):4195-4200 DOI $10.1242 /$ jcs.023820.

Gao W, Zhang C, Li W, Li H, Sang J, Zhao Q, Bo Y, Luo H, Zheng X, Lu Y, Shi Y, Yang D, Zhang R, Li Z, Cui J, Zhang Y, Niu M, Li J, Wu Z, Guo H, Xiang C, Wang J, Hou J, Zhang L, Thorne RF, Cui Y, Wu Y, Wen S, Wang B. 2019. Promoter Methylation-Regulated miR-145-5p Inhibits Laryngeal Squamous Cell Carcinoma Progression by Targeting FSCN1. Molecular therapy : the journal of the American Society of Gene Therapy 27(2):365-379 DOI 10.1016/j.ymthe.2018.09.018.

Golubovskaya VM, Cance WG. 2013. Targeting the p53 pathway. Surgical oncology clinics of North America 22(4):747-764 DOI 10.1016/j.soc.2013.06.003.

Guan GF, Zheng Y, Wen LJ, Zhang DJ, Yu DJ, Lu YQ, Zhao Y, Zhang H. 2015. Gene expression profiling via bioinformatics analysis reveals biomarkers in laryngeal squamous cell carcinoma. Molecular medicine reports 12(2):2457-2464 DOI 10.3892/mmr.2015.3701.

He Y, Liang D, Li D, Shan B, Zheng R, Zhang S, Wei W, He J. 2020. Incidence and mortality of laryngeal cancer in China, 2015. Chinese journal of cancer research = Chung-kuo yen cheng yen chiu 32(1):10-17 DOI 10.21147/j.issn.10009604.2020.01.02.

Huang C, Wang Z, Zhang K, Dong Y, Zhang A, Lu C, Liu L. 2020. MicroRNA-107 inhibits proliferation and invasion of laryngeal squamous cell carcinoma cells by targeting CACNA2D1 in vitro. Anti-cancer drugs 31(3):260-271 DOI 10.1097/CAD.0000000000000865. 
341 Huangfu H, Pan H, Wang B, Wen S, Han R, Li L. 2016. Association between UGT1A1 Polymorphism and Risk of Laryngeal Squamous Cell Carcinoma. International journal of environmental research and public health 13(1)DOI 10.3390/ijerph13010112.

Jiang W, Li T, Wang J, Jiao R, Shi X, Huang X, Ji G. 2019. miR-140-3p Suppresses Cell Growth And Induces Apoptosis In Colorectal Cancer By Targeting PD-L1. OncoTargets and therapy 12:10275-10285 DOI 10.2147/OTT.S226465.

Jin T, Hu WH, Guo LB, Chen WK, Li QL, Lin H, Cai XY, Ge N, Sun R, Bu SY, Zhang X, Qiu MY, Zhang W, Luo S, Zhou YX. 2011. Treatment results and prognostic factors of patients undergoing postoperative radiotherapy for laryngeal squamous cell carcinoma. Chinese journal of cancer 30(7):482-489 DOI 10.5732/cjc.010.10527.

Kanehisa M, Goto S. 2000. KEGG: kyoto encyclopedia of genes and genomes. Nucleic acids research 28(1):27-30 DOI $10.1093 / \mathrm{nar} / 28.1 .27$.

Kar S. 2016. Unraveling Cell-Cycle Dynamics in Cancer. Cell systems 2(1):8-10 DOI 10.1016/j.cels.2016.01.007.

Khatri P, Sirota M, Butte AJ. 2012. Ten years of pathway analysis: current approaches and outstanding challenges. $P L O S$ computational biology 8(2):e1002375 DOI 10.1371/journal.pcbi.1002375.

Kontić M, Čolović Z, Paladin I, Gabelica M, Barić A, Pešutić-Pisac V. 2019. Association between EGFR expression and clinical outcome of laryngeal HPV squamous cell carcinoma. Acta oto-laryngologica 139(10):913-917 DOI 10.1080/00016489.2019.1651938.

Lampri ES, Chondrogiannis G, Ioachim E, Varouktsi A, Mitselou A, Galani A, Briassoulis E, Kanavaros P, Galani V. 2015. Biomarkers of head and neck cancer, tools or a gordian knot. International journal of clinical and experimental medicine 8(7): 10340-10357

Lee RC, Feinbaum RL, Ambros V. 1993. The C. elegans heterochronic gene lin-4 encodes small RNAs with antisense complementarity to lin-14. Cell 75(5):843-854 DOI 10.1016/0092-8674(93)90529-y. 
362 Li FJ, Cai ZJ, Yang F, Zhang SD, Chen M. 2016. Th17 expression and IL-17 levels in laryngeal squamous cell carcinoma patients. Acta oto-laryngologica 136(5):484-490 DOI 10.3109/00016489.2015.1126857.

Li P, Liu H, Wang Z, He F, Wang H, Shi Z, Yang A, Ye J. 2016. MicroRNAs in laryngeal cancer: implications for diagnosis, prognosis and therapy. American Journal of Translational Research 8(5):1935-1944

Li X, Abdel-Mageed AB, Mondal D, Kandil E. 2013. MicroRNA expression profiles in differentiated thyroid cancer, a review. International journal of clinical and experimental medicine 6(1):74-80 OncoTargets and therapy 12:10441-10453 DOI 10.2147/OTT.S224325.

Lin X, Chen Y. 2018. Identification of Potentially Functional CircRNA-miRNA-mRNA Regulatory Network in Hepatocellular Carcinoma by Integrated Microarray Analysis. Medical science monitor basic research 24:70-78 DOI 10.12659/MSMBR.909737.

Liu Y, Ye F. 2019. Construction and integrated analysis of crosstalking ceRNAs networks in laryngeal squamous cell carcinoma. PeerJ 7:e7380 DOI 10.7717/peerj.7380.

Ma J, Hu X, Dai B, Wang Q, Wang H. 2021. Bioinformatics analysis of laryngeal squamous cell carcinoma: seeking key candidate genes and pathways. PeerJ 9:e11259 DOI 10.7717/peerj.11259.

Ma J, Zhang F, Sun P. 2020. miR-140-3p impedes the proliferation of human cervical cancer cells by targeting RRM2 to induce cell-cycle arrest and early apoptosis. Bioorganic \& medicinal chemistry 28(3):115283 DOI 10.1016/j.bmc.2019.115283.

Münger K, Baldwin A, Edwards KM, Hayakawa H, Nguyen CL, Owens M, Grace M, Huh K. 2004. Mechanisms of human papillomavirus-induced oncogenesis. Journal of virology 78(21):11451-11460 DOI 10.1128/JVI.78.21.1145111460.2004 . 
383

384

385

386

387

388

389

390

391

392

393

394

395

396

397

398

399

400

401

402

403

404

405

\section{Pawlowska E, Janik-Papis K, Rydzanicz M, Zuk K, Kaczmarczyk D, Olszewski J, Szyfter K, Blasiak J, Morawiec-} Sztandera A. 2009. The Cys326 allele of the 8-oxoguanine DNA N-glycosylase 1 gene as a risk factor in smoking- and drinking-associated larynx cancer. The Tohoku journal of experimental medicine 219(4):269-275 DOI 10.1620/tjem.219.269.

Qadir MI, Faheem A. 2017. miRNA: A Diagnostic and Therapeutic Tool for Pancreatic Cancer. Critical reviews in eukaryotic gene expression 27(3):197-204 DOI 10.1615/CritRevEukaryotGeneExpr.2017019494.

Qu X, Gao D, Ren Q, Jiang X, Bai J, Sheng L. 2018. miR-211 inhibits proliferation, invasion and migration of cervical cancer via targeting SPARC. Oncology letters 16(1):853-860 DOI 10.3892/ol.2018.8735.

Sabitha K, Reddy MV, Jamil K. 2010. Smoking related risk involved in individuals carrying genetic variants of CYP1A1 gene in head and neck cancer. Cancer epidemiology 34(5):587-592 DOI 10.1016/j.canep.2010.05.002.

Salem O, Erdem N, Jung J, Münstermann E, Wörner A, Wilhelm H, Wiemann S, Körner C. 2016. The highly expressed 5'isomiR of hsa-miR-140-3p contributes to the tumor-suppressive effects of miR-140 by reducing breast cancer proliferation and migration. BMC genomics 17:566 DOI 10.1186/s12864-016-2869-x.

Tong F, Geng J, Yan B, Lou H, Chen X, Duan C, He J, Zhang S, Xie H, Li H, Yuan D, Zhang F, Meng H, Wei L. 2018. Prevalence and Prognostic Significance of HPV in Laryngeal Squamous Cell Carcinoma in Northeast China. Cellular physiology and biochemistry : international journal of experimental cellular physiology, biochemistry, and pharmacology 49(1):206-216 DOI 10.1159/000492858.

Vishnoi A, Rani S. 2017. MiRNA Biogenesis and Regulation of Diseases: An Overview. Methods in molecular biology 1509:110 DOI 10.1007/978-1-4939-6524-3_1.

Walker C, Mojares E, Del Río Hernández A. 2018. Role of Extracellular Matrix in Development and Cancer Progression. International journal of molecular sciences 19(10)DOI 10.3390/ijms19103028.

Wang J, Yan Y, Zhang Z, Li Y. 2019. Role of miR-10b-5p in the prognosis of breast cancer. PeerJ 7:e7728 DOI 10.7717 peerj. 7728 .

Peer] reviewing PDF | (2021:03:59406:2:1:NEW 23 Jul 2021) 
406 Wang Y, Shang S, Yu K, Sun H, Ma W, Zhao W. 2020. miR-224, miR-147b and miR-31 associated with lymph node metastasis and prognosis for lung adenocarcinoma by regulating PRPF4B, WDR82 or NR3C2. PeerJ 8:e9704 DOI

Wang Y, Yang J, Xu H. 2013. [Expression of IL-17 in laryngeal squamous cell carcinoma tissues and the clinical significance]. Lin chuang er bi yan hou tou jing wai ke za zhi = Journal of clinical otorhinolaryngology, head, and neck surgery 27(14):779-783

Wei KR, Zheng RS, Liang ZH, Sun KX, Zhang SW, Li ZM, Zeng HM, Zou XN, Chen WQ, He J. 2018. [Incidence and mortality of laryngeal cancer in China, 2014]. Zhonghua zhong liu za zhi [Chinese journal of oncology] 40(10):736-743 DOI 10.3760/cma.j.issn.0253-3766.2018.10.004.

Wienholds E, Kloosterman WP, Miska E, Alvarez-Saavedra E, Berezikov E, de Bruijn E, Horvitz HR, Kauppinen S, Plasterk RH. 2005. MicroRNA expression in zebrafish embryonic development. Science 309(5732):310-311 DOI $10.1126 /$ science. 1114519 .

Wu Y, Yu J, Ma Y, Wang F, Liu H. 2016. miR-148a and miR-375 may serve as predictive biomarkers for early diagnosis of laryngeal carcinoma. Oncology letters 12(2):871-878 DOI 10.3892/o1.2016.4707.

Xiong D, Wu W, Kan L, Chen D, Dou X, Ji X, Wang M, Zong Z, Li J, Zhang X. 2020. LINC00958 and HOXC13-AS as key candidate biomarkers in head and neck squamous cell carcinoma by integrated bioinformatics analysis. PeerJ 8:e8557 DOI $10.7717 /$ peerj.8557.

Yang J, Zhou L, Zhang Y, Zheng J, Zhou J, Wei Z, Zou J. 2019. DIAPH1 Is Upregulated and Inhibits Cell Apoptosis through ATR/p53/Caspase-3 Signaling Pathway in Laryngeal Squamous Cell Carcinoma. Disease markers 2019:6716472 DOI $10.1155 / 2019 / 6716472$

Yu X, Wu Y, Liu Y, Deng H, Shen Z, Xiao B, Guo J. 2014. miR-21, miR-106b and miR-375 as novel potential biomarkers for laryngeal squamous cell carcinoma. Current pharmaceutical biotechnology 15(5):503-508 DOI 
429 Zhang B, Fu T, Zhang L. 2018. MicroRNA-153 suppresses human laryngeal squamous cell carcinoma migration and invasion by targeting the SNAI1 gene. Oncology letters 16(4):5075-5083 DOI 10.3892/ol.2018.9302.

431

432

Zhang W, Zou C, Pan L, Xu Y, Qi W, Ma G, Hou Y, Jiang P. 2015. MicroRNA-140-5p inhibits the progression of colorectal cancer by targeting VEGFA. Cellular physiology and biochemistry : international journal of experimental cellular physiology, biochemistry, and pharmacology 37(3):1123-1133 DOI 10.1159/000430237.

Zhao Q, Zheng X, Guo H, Xue X, Zhang Y, Niu M, Cui J, Liu H, Luo H, Yang D, Shi Y, Huangfu H, Wen S, Wu Y, Gao W, Wang B. 2020. Serum Exosomal miR-941 as a promising Oncogenic Biomarker for Laryngeal Squamous Cell Carcinoma. Journal of Cancer 11(18):5329-5344 DOI 10.7150/jca.45394.

Zhao Y, Tao Z, Chen X. 2020. Identification of the miRNA-mRNA regulatory pathways and a miR-21-5p based nomogram model in clear cell renal cell carcinoma. PeerJ 8:e10292 DOI 10.7717/peerj.10292. 


\section{Figure 1}

Volcanic map of differentially expressed miRNA.

Orange represents upregulated miRNAs, blue represents downregulated miRNAs, and black represents miRNAs without a significant difference in expression. 


\section{Volcano}

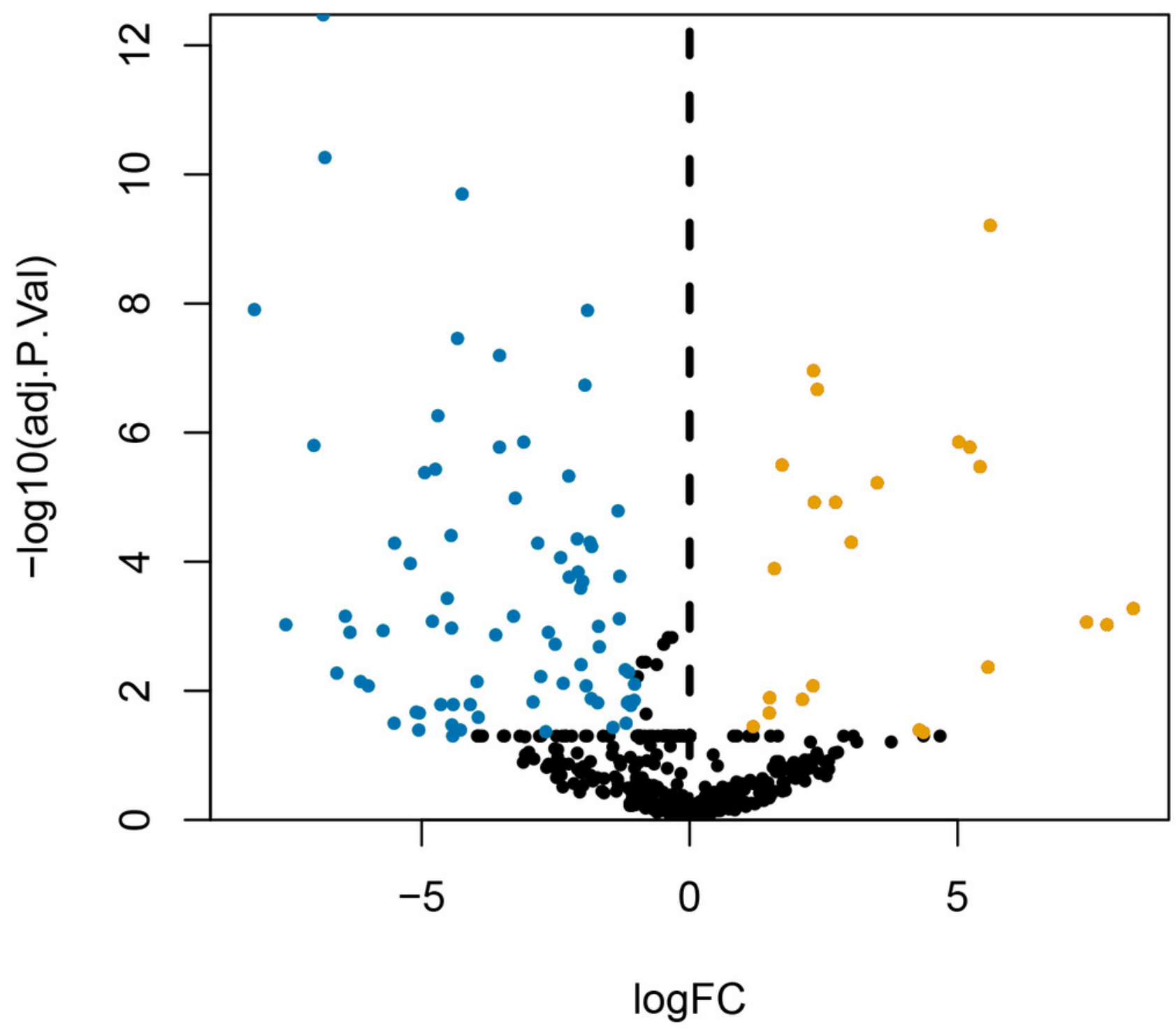


Figure 2

Volcanic map of differentially expressed mRNAs.

Orange represents upregulated mRNAs, blue represents downregulated mRNAs, and black represents mRNAs without a significant difference in expression. 


\section{Volcano}

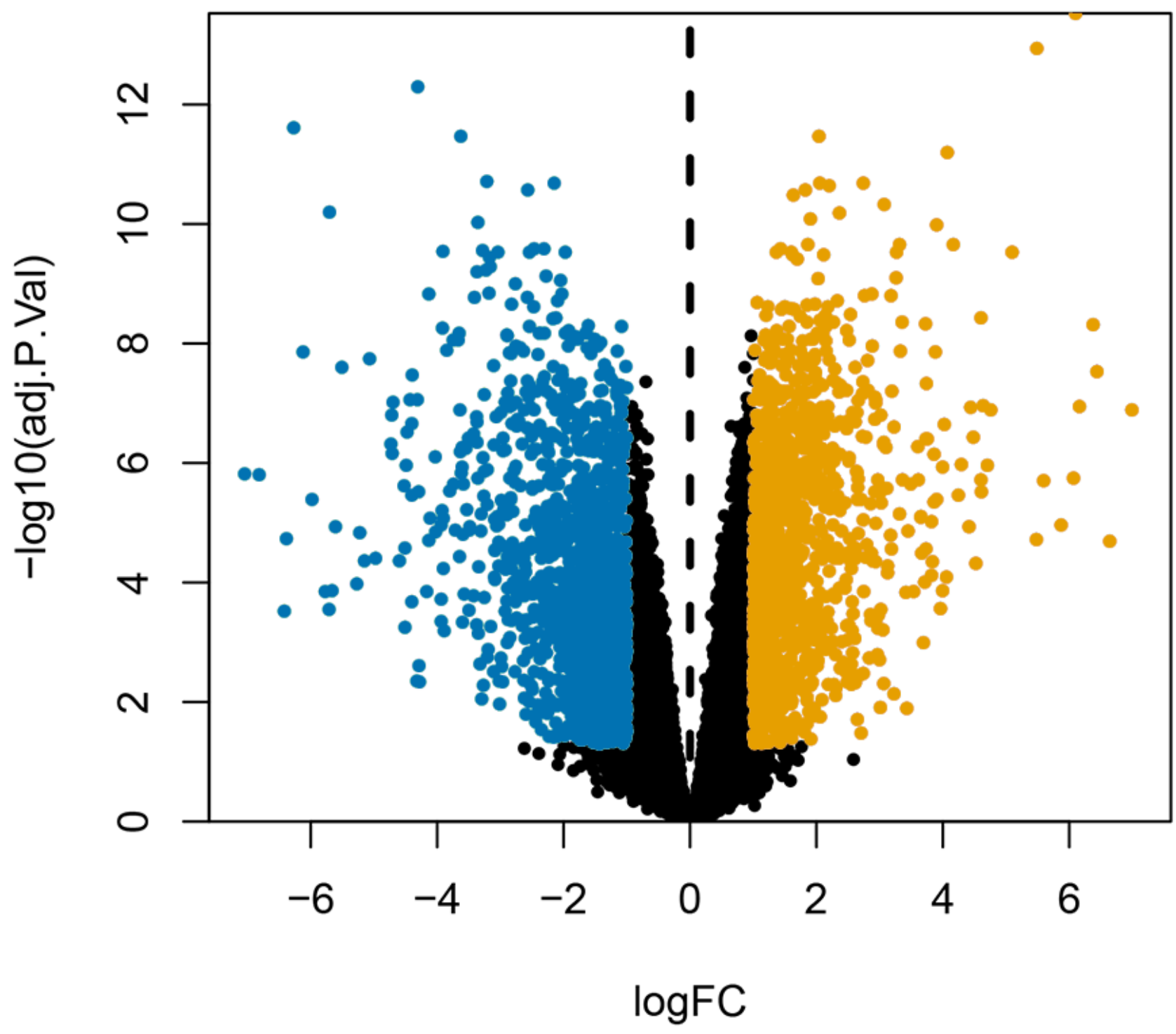


Figure 3

The miRNA-mRNA regulatory network.

Ellipses represent mRNAs, triangles represent miRNAs, orange represents upregulated expression, blue represents downregulated expression, and connected lines represent targeted relationship.

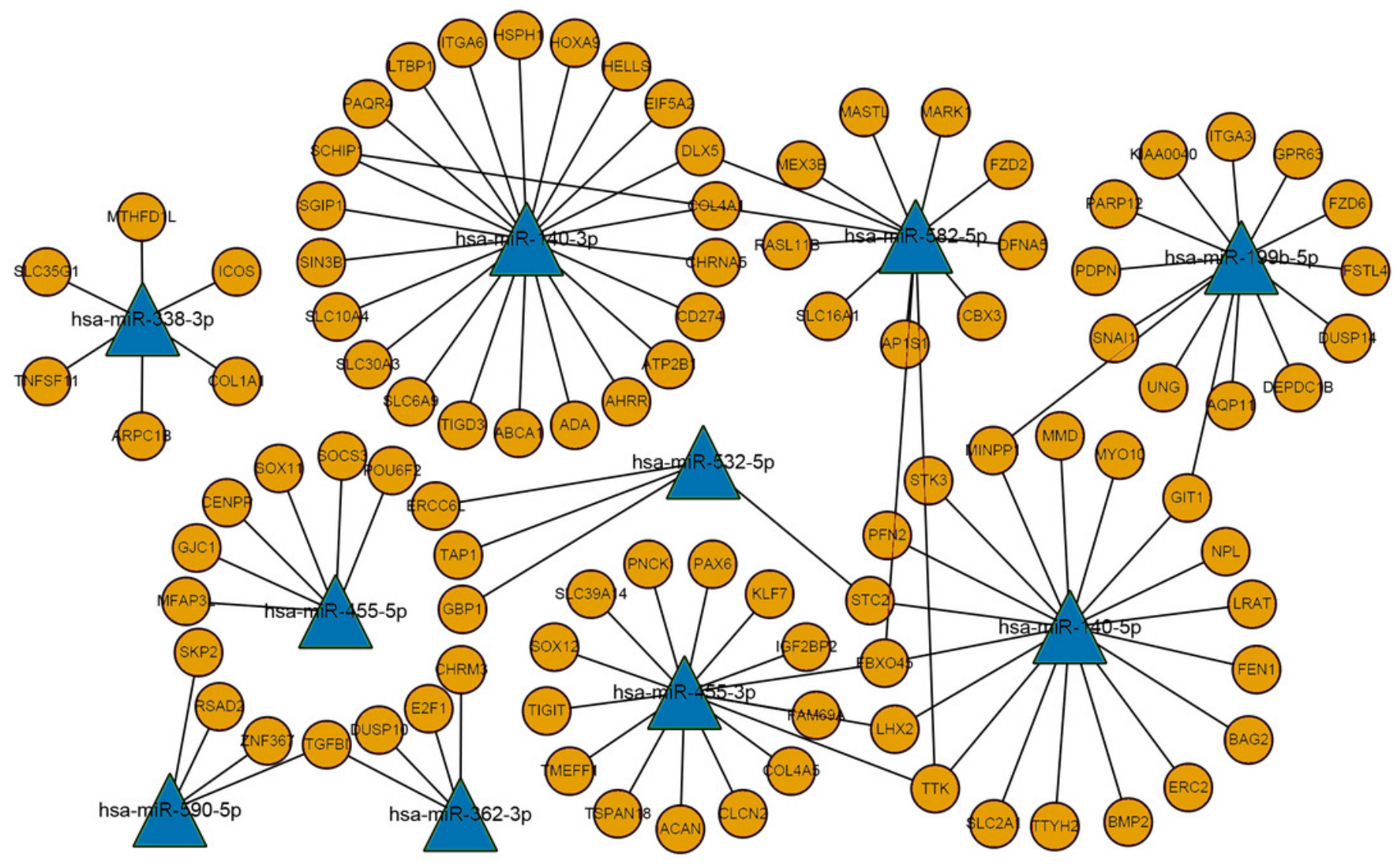




\section{Figure 4}

\section{GO enrichment analysis of differentially expressed mRNAs.}

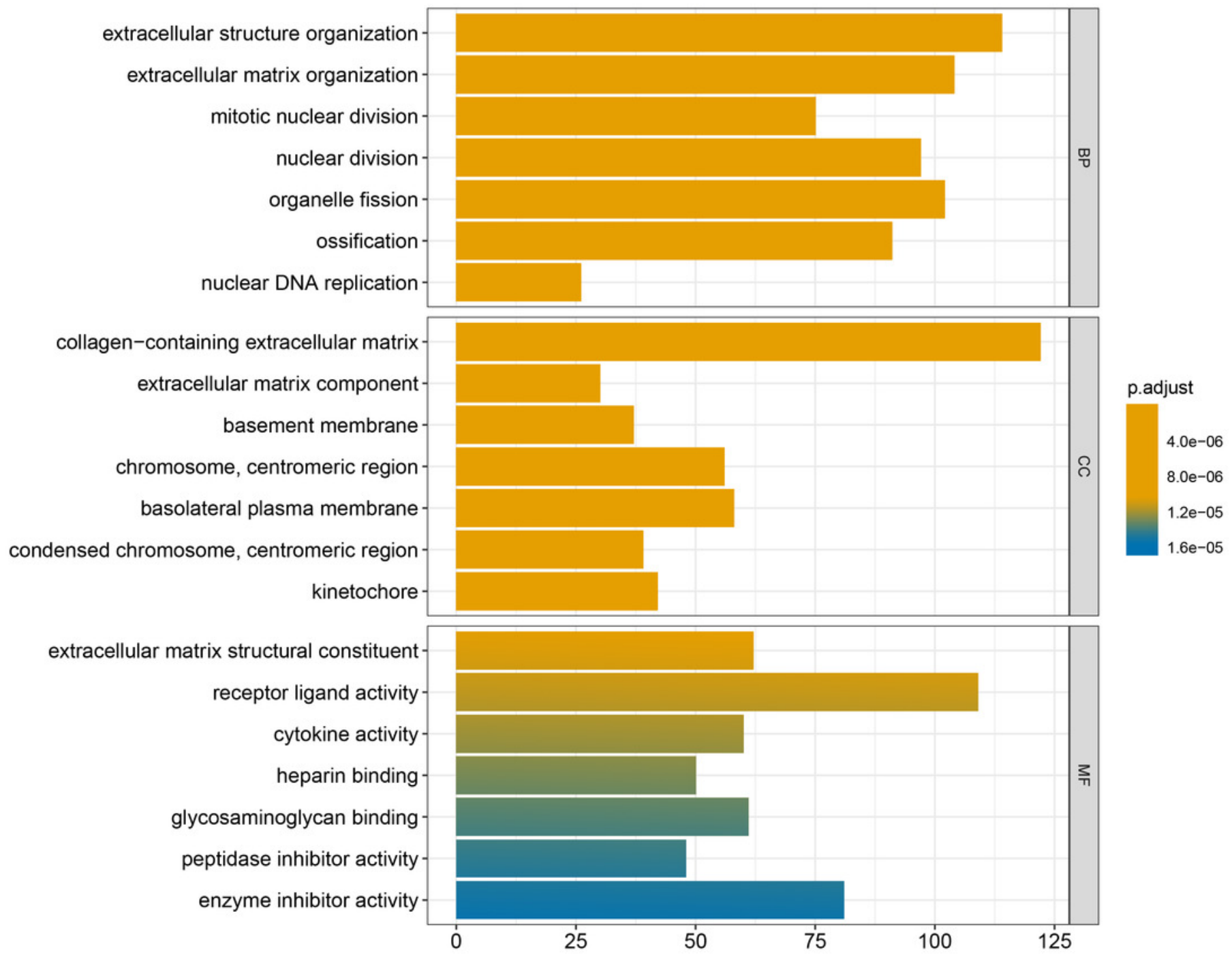


Figure 5

\section{KEGG enrichment analysis of differentially expressed mRNAs.}

Cytokine-cytokine receptor interaction DNA replication

Cell cycle

ECM-receptor interaction

Small cell lung cancer

Viral protein interaction with cytokine and cytokine receptor

Retinol metabolism

Amoebiasis

Drug metabolism - cytochrome P450 Metabolism of xenobiotics by cytochrome P450-

Chemical carcinogenesis

IL-17 signaling pathway

Salivary secretion

Protein digestion and absorption

Progesterone-mediated oocyte maturation

p53 signaling pathway

Complement and coagulation cascades

Staphylococcus aureus infection

$\mathrm{ABC}$ transporters

AGE-RAGE signaling pathway in diabetic complications

Focal adhesion

Chemokine signaling pathway

beta-Alanine metabolism

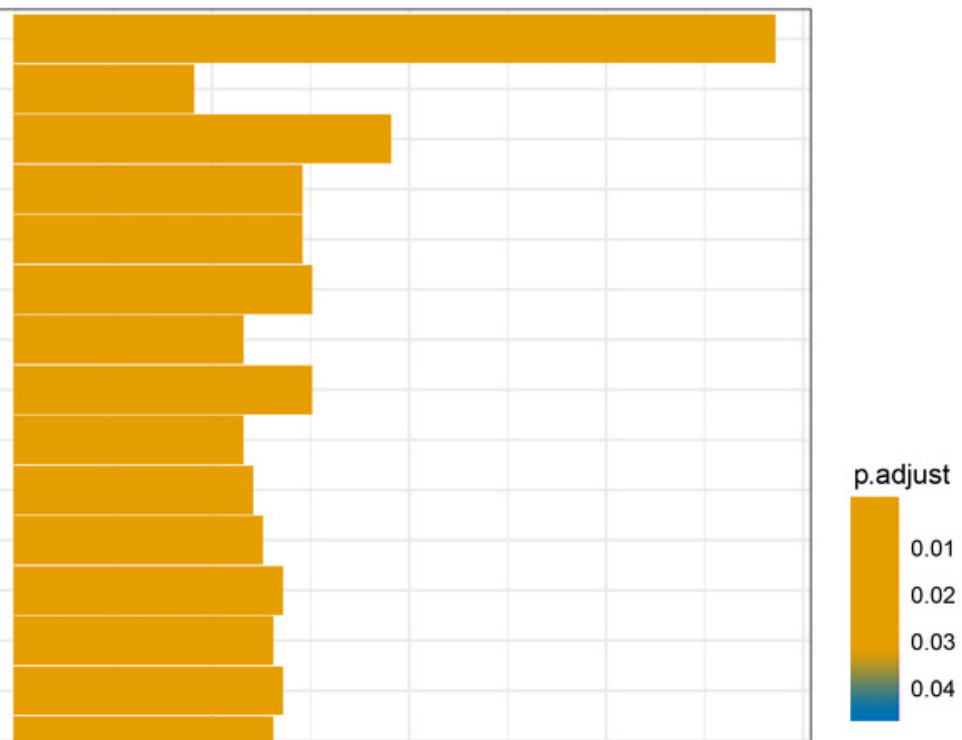




\section{Figure 6}

The expression of miR-140-3p in HLECs and LSC-1 cells was measured using the QRTPCR assay. $\left(* p<0.05, * * p<0.01\right.$, and $\left.{ }^{* * *} p<0.001\right)$.

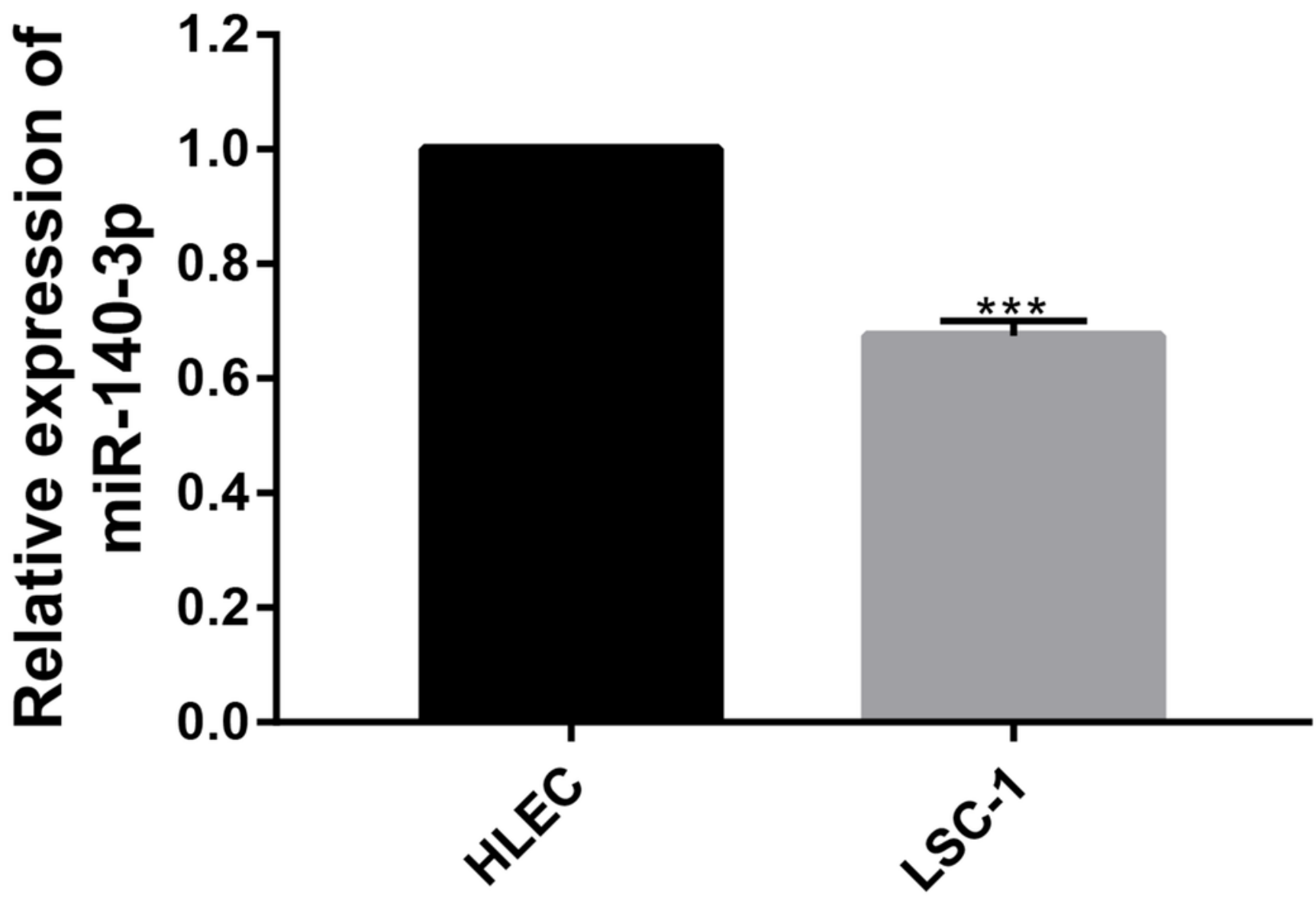


Figure 7

MiR-140-3p and miR-NC were transfected into LSC-1 cells, respectively, and the expression of miR-140-3p was detected by QRT- PCR. $(* p<0.05, * * p<0.01$, and $* * * p<$ 0.001).

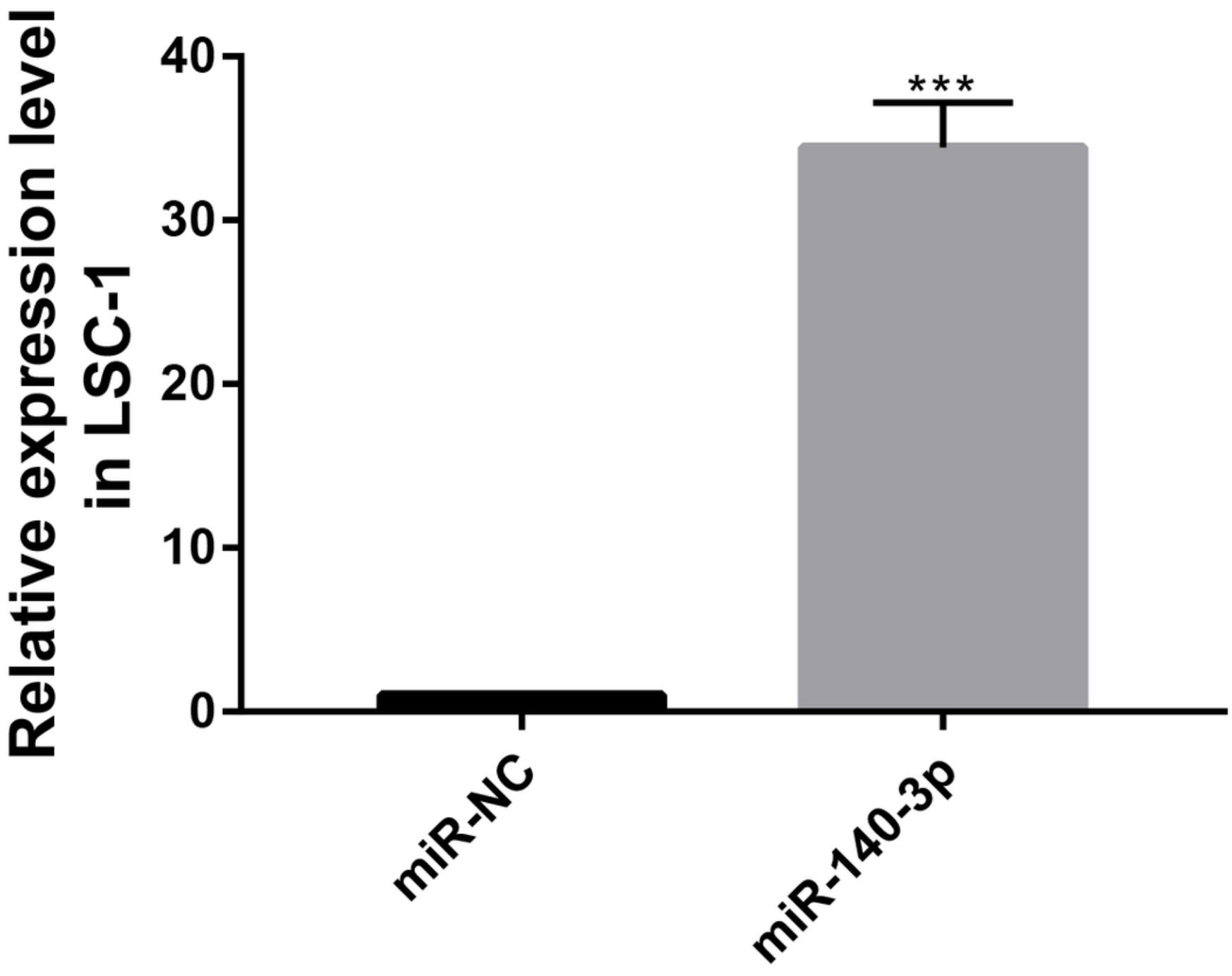


Figure 8

Effects of miR-140-3p on LSC-1 cell proliferation in vitro. ${ }^{*} p<0.05$.

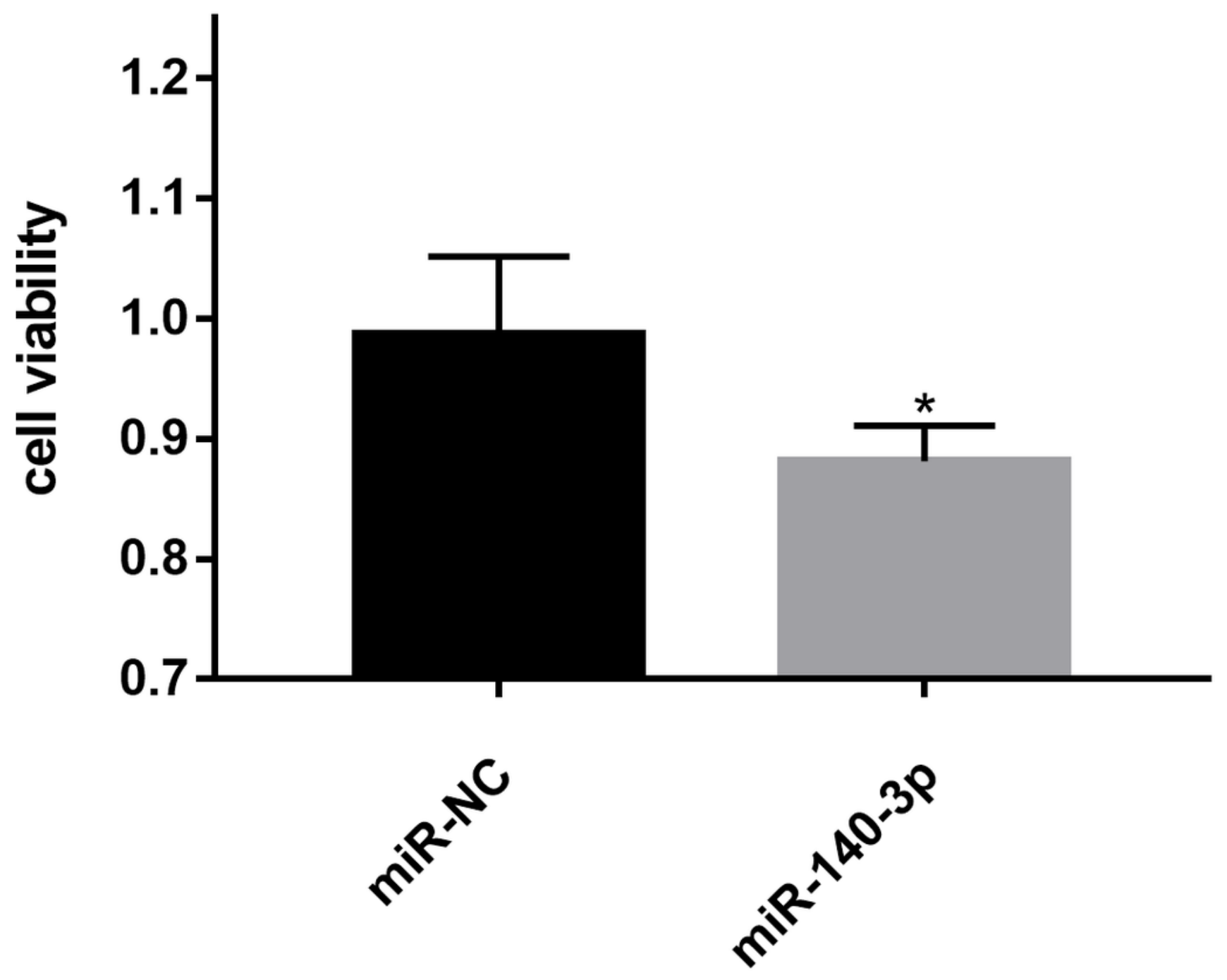


Figure 9

LSC-1 cells were transfected with miR-140-3p and miR-NC, respectively, and Annexin VFITC and PI staining were performed to detect the percentage of cell apoptosis by flow cytometry. ( ${ }^{*} p<0.05, * * p<0.01$, and $\left.{ }^{* * *} p<0.001\right)$.

miR-NC

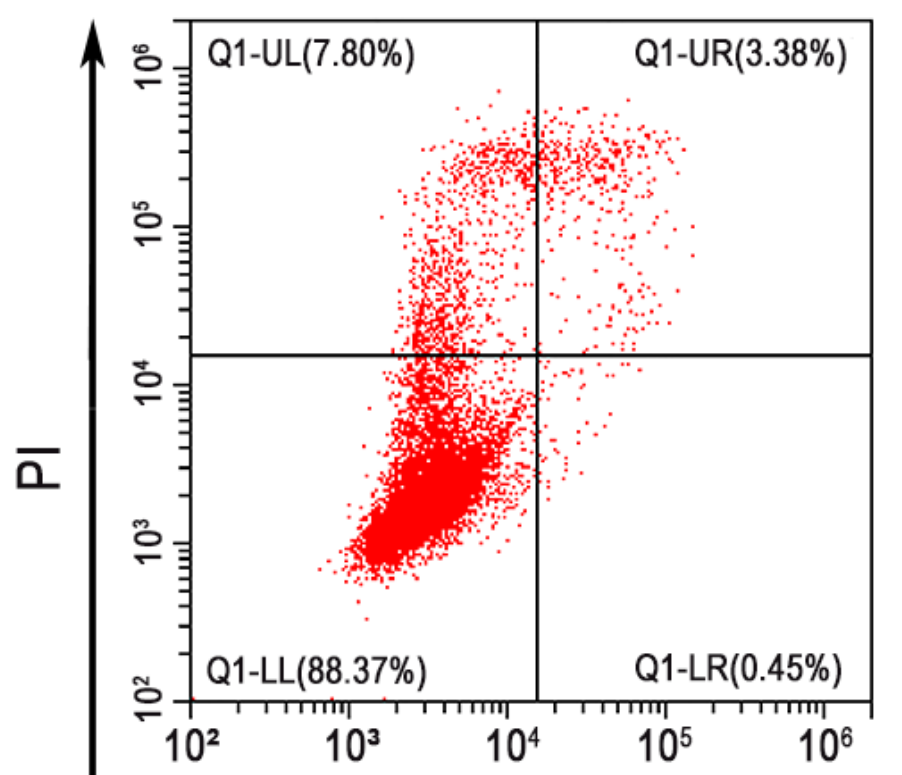

$\operatorname{miR}-140-3 p$

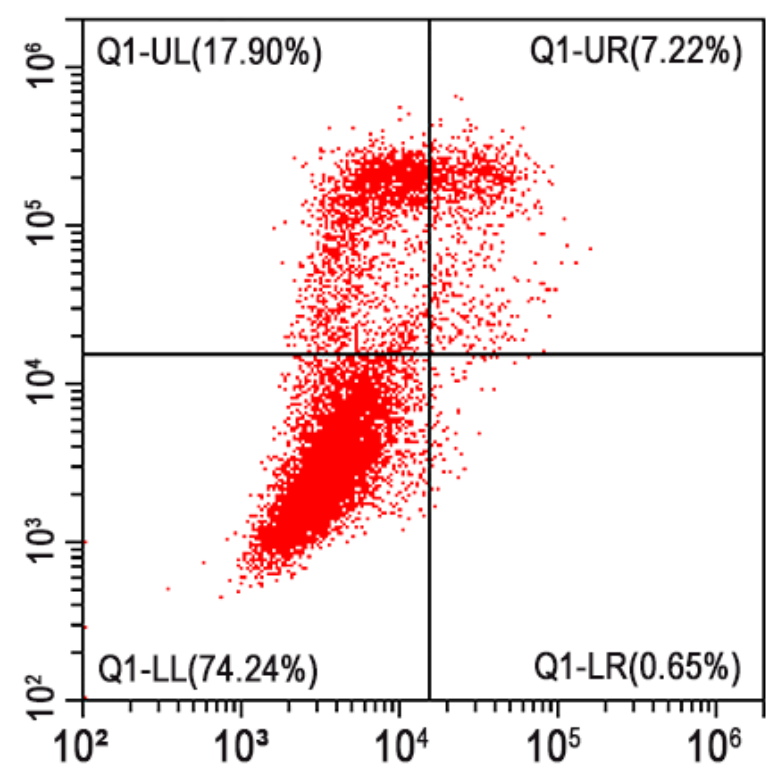

Annexin $\mathrm{V}$

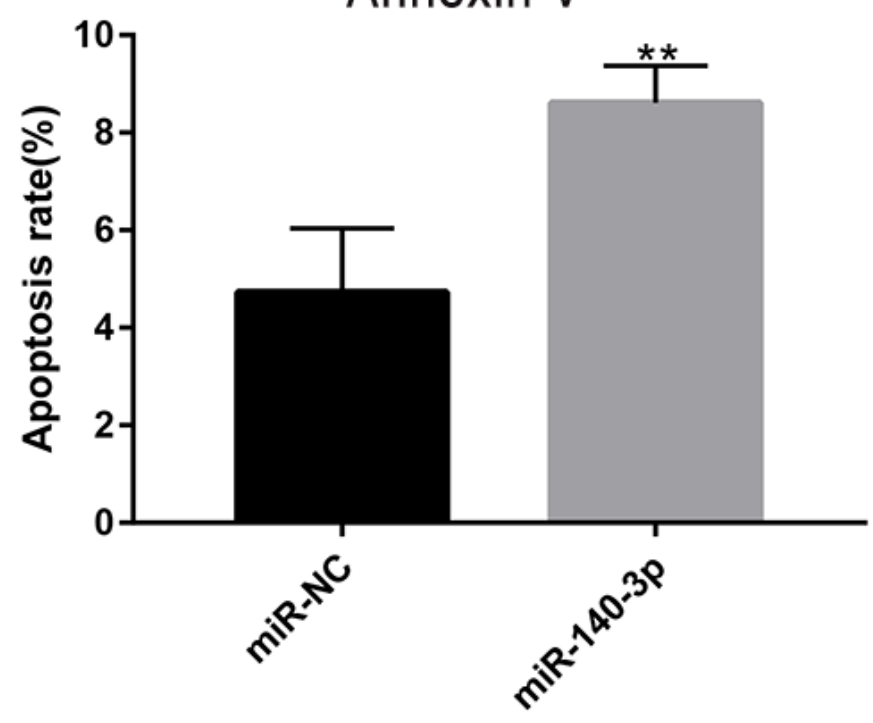




\section{Table $\mathbf{1}$ (on next page)}

Table $1 \mathrm{GO}$ and KEGG pathway enrichment analysis of differentially expressed mRNAs in LSCC. 


\begin{tabular}{|c|c|c|c|}
\hline Pathway ID & Pathway description & P-Value & Count \\
\hline GO:0043062 & extracellular structure organization & $5.33 \mathrm{E}-19$ & 114 \\
\hline GO:0030198 & extracellular matrix organization & $5.81 \mathrm{E}-19$ & 104 \\
\hline GO:0140014 & mitotic nuclear division & $3.60 \mathrm{E}-14$ & 75 \\
\hline GO:0000280 & nuclear division & $1.08 \mathrm{E}-12$ & 97 \\
\hline GO:0048285 & organelle fission & $6.24 \mathrm{E}-12$ & 102 \\
\hline GO:0001503 & ossification & $6.03 \mathrm{E}-11$ & 91 \\
\hline GO:0033260 & nuclear DNA replication & $4.25 \mathrm{E}-10$ & 26 \\
\hline GO:0062023 & collagen-containing extracellular matrix & $6.46 \mathrm{E}-25$ & 122 \\
\hline GO:0044420 & extracellular matrix component & $3.96 \mathrm{E}-16$ & 30 \\
\hline GO:0005604 & basement membrane & $3.44 \mathrm{E}-12$ & 37 \\
\hline GO:0000775 & chromosome, centromeric region & $1.75 \mathrm{E}-11$ & 56 \\
\hline GO:0016323 & basolateral plasma membrane & $2.77 \mathrm{E}-10$ & 58 \\
\hline GO:0000779 & condensed chromosome, centromeric region & 3.07E-10 & 39 \\
\hline GO:0000776 & kinetochore & $5.46 \mathrm{E}-10$ & 42 \\
\hline GO:0005201 & extracellular matrix structural constituent & $1.52 \mathrm{E}-17$ & 62 \\
\hline GO:0048018 & receptor ligand activity & 4.03E-11 & 109 \\
\hline GO:0005125 & cytokine activity & $6.52 \mathrm{E}-10$ & 60 \\
\hline GO:0008201 & heparin binding & $8.39 \mathrm{E}-10$ & 50 \\
\hline GO:0005539 & glycosaminoglycan binding & $1.29 \mathrm{E}-09$ & 61 \\
\hline GO:0030414 & peptidase inhibitor activity & $1.01 \mathrm{E}-07$ & 48 \\
\hline GO:0004857 & enzyme inhibitor activity & $1.09 \mathrm{E}-07$ & 81 \\
\hline hsa04060 & Cytokine-cytokine receptor interaction & $4.96 \mathrm{E}-10$ & 77 \\
\hline hsa03030 & DNA replication & $8.60 \mathrm{E}-08$ & 18 \\
\hline hsa04110 & Cell cycle & $1.75 \mathrm{E}-07$ & 38 \\
\hline hsa04512 & ECM-receptor interaction & $9.49 \mathrm{E}-07$ & 29 \\
\hline hsa05222 & Small cell lung cancer & $2.65 \mathrm{E}-06$ & 29 \\
\hline hsa04061 & $\begin{array}{l}\text { Viral protein interaction with cytokine and cytokine } \\
\text { receptor }\end{array}$ & $5.56 \mathrm{E}-06$ & 30 \\
\hline hsa00830 & Retinol metabolism & $7.66 \mathrm{E}-06$ & 23 \\
\hline hsa05146 & Amoebiasis & 8.64E-06 & 30 \\
\hline hsa00982 & Drug metabolism - cytochrome P450 & $2.22 \mathrm{E}-05$ & 23 \\
\hline hsa00980 & Metabolism of xenobiotics by cytochrome P450 & 2.99E-05 & 24 \\
\hline hsa05204 & Chemical carcinogenesis & 3.07E-05 & 25 \\
\hline hsa04657 & IL-17 signaling pathway & 3.84E-05 & 27 \\
\hline hsa04970 & Salivary secretion & $8.78 \mathrm{E}-05$ & 26 \\
\hline hsa04974 & Protein digestion and absorption & 0.0002 & 27 \\
\hline hsa04914 & Progesterone-mediated oocyte maturation & 0.0003 & 26 \\
\hline hsa04115 & p53 signaling pathway & 0.0007 & 20 \\
\hline hsa04610 & Complement and coagulation cascades & 0.0009 & 22 \\
\hline hsa05150 & Staphylococcus aureus infection & 0.0009 & 24 \\
\hline
\end{tabular}




\begin{tabular}{cccc}
\hline hsa02010 & ABC transporters & 0.0011 & 14 \\
hsa04933 & AGE-RAGE signaling pathway in diabetic & 0.0017 & 24 \\
hsa04510 & complications & 0.0018 & 41 \\
hsa04062 & Focal adhesion & 0.0026 & 39 \\
\hline
\end{tabular}

1 